\title{
Oxygen Toxicity: Comparison of Lung Biochemical Responses in Neonatal and Adult Rats
}

\author{
JOHN YAM, LEE FRANK, AND ROBERT J. ROBERTS(41) \\ Division of Pediatric Clinical Pharmacology, The Toxicology Center, Departments of Pharmacology and \\ Pediatrics, The University of lowa, lowa City, Iowa, USA
}

\begin{abstract}
Summary
Neonatal rats (4-7 days old) and adult rats (approximately 80 days old) were continuously exposed to either 96-98\% oxygen or air. Examination of the lungs of neonatal rats, who survived 5 days of oxygen exposure with no evidence of respiratory distress, showed significant increases in the pulmonary superoxide dismutase (SOD) activity (peak value: $144 \%$ of airexposed controls), glutathione peroxidase (GP) activity (126\%), glutathione reductase $(\mathrm{GR})$ activity $(122 \%)$, reduced glutathione (GSH) level (176\%), and glucose-6-phosphate dehydrogenase activity $(151 \%)$. Adult rats, most of whom succumbed within 3 days of oxygen exposure, did not show any significant increase in the activities of pulmonary SOD, GP, GR, and the level of GSH as compared to the air-exposed adult animals. Glucose-6-phosphate dehydrogenase was significantly elevated in the 72-hr oxygen-exposed adult rats. It is concluded that increases in the lung complement of SOD, GR, GP, and GSH in the neonatal rat during oxygen challenge may provide the mechanism(s) for their increased tolerance to hyperoxia-induced lung injury as compared to the adults.
\end{abstract}

\section{Speculation}

Further knowledge about the role of the antioxidant defense mechanism(s) of the neonatal lung may have important implications in the pursuit of the etiology of neonatal respiratory disease and in the identification of agent(s) that may minimize pulmonary toxicity associated with oxygen therapy.

The toxic consequences of oxygen therapy have long been a subject of intensive clinical and experimental concern $(5,14$, $38)$. Considerable evidence exists which links oxygen to the development of two neonatal diseases: retrolental fibroplasia (14) and bronchopulmonary dysplasia $(26,39)$. Although past research efforts have concentrated mainly on the characterization of the histopathology of oxygen toxicity, recent work has been directed towards the understanding of the biochemical mechanism of oxygen toxicity. It is now generally believed that oxygen-induced cell toxicity is the result of the formation of highly reactive free radicals $(9,35)$.

Superoxide anion $\left(\mathrm{O}_{2}^{-}\right)$, a highly reactive free radical formed in the cell by univalent reduction of oxygen, has generally been suspected as a prime causative agent in oxygen-induced cell toxicity $(9,35)$. During prolonged high oxygen exposure, superoxide anion is thought to react with polyunsaturated lipids in the cell, particularly those in cell membranes, thereby initiating a chain reaction of lipid peroxidation, which subsequently leads to destruction of essential cellular components and disruption of normal cellular functions $(4,9)$. Superoxide anion and its toxic byproducts may further upset the homeostasis of the cell either by denaturation of intracellular enzymes and/or nucleoproteins (20) or by some other cytotoxic reaction. Other reactive secondary products of superoxide anion, hydroxyl radical $(\mathrm{OH} \cdot)$, peroxy radical (HOO $)$, hydrogen peroxide $\left(\mathrm{H}_{2} \mathrm{O}_{2}\right)$, and singlet oxygen $\left({ }^{1} \mathrm{O}_{2}\right)$, have also been suggested to participate in oxygen-induced cell damage $(9,17)$.

These free radical-induced cytotoxic reactions, however, do not proceed uncontrolled. It is believed that oxygen-metabolizing cells possess antioxidant protective mechanisms which minimize the toxicity of free radicals and lipid peroxides by converting them to less toxic substances $(6,9,15,35)$. Of all the cells in the body, the greatest challenge to these protective systems would occur in the cells of the lung, since these cells are exposed to the highest concentrations of oxygen in the body during either normoxic or hyperoxic conditions.

There are at least two potential protective antioxidant defense mechanisms present in the cells of the lung that may offset oxygen-induced cell injury. One mechanism involves the enzyme, SOD (EC 1.15.11). SOD catalyzes, by dismutation, the reaction:

$$
2 \mathrm{O}_{2}^{-}+2 \mathrm{H}^{+} \rightarrow \mathrm{H}_{2} \mathrm{O}_{2}+\mathrm{O}_{2}
$$

SOD has been proposed to play an important role in the detoxification of oxygen both in the microorganism $(24,35)$ and in mammalian species $(1,6,7,11,15,33,37)$. As the production of superoxide anion exceeds the capacity of the defense mechanism, i.e., SOD, some superoxide anion may escape dismutation and initiate lipid peroxidation with the resultant formation of toxic lipid peroxides.

To further protect the lung from injury by lipid peroxides, the glutathione system, which consists of a battery of enzymes, functions as an additional antioxidant defense mechanism in the lung. The first enzyme in this system, GP (EC 1.11.1.9.), is generally thought to reduce the toxic lipid peroxides to the correspondingly less toxic hydroxy fatty acids, utilizing GSH as a cofactor $(3,15)$. Recent evidence, however, suggests that GP may exert its primary effect by preventing free radical attack on polyunsaturated membrane lipids rather than by reducing membrane lipid peroxides to hydroxy fatty acids (22). A second enzyme, GR (EC 1.6.4.2), is necessary to regenerate the pool of GSH by reducing oxidized glutathione at the expense of NADPH. The depleted NADPH may then be replenished by one of several cellular enzymatic reactions including glucose-6phosphate dehydrogenase (G-6-PD, EC 1.1.1.49).

It has long been recognized that the immature animal, although not totally immune to oxygen toxicity, is nevertheless more resistant to oxygen-induced lung damage than the adult $(2,5,12,18,29,40)$. We have previously observed that exposure of young animals to only $24 \mathrm{hr}$ of $85 \%$ oxygen produced a significant increase in pulmonary SOD activity which was not seen in adult animals exposed under identical 
conditions (11). We postulated that the rapid increase in pulmonary SOD activity in young animals during hyperoxic exposure may be an important factor accounting for their reduced susceptibility to pulmonary hyperoxic injury compared to the older animal (11). To further test this hypothesis, and to extend the study to the glutathione system, we have examined in the present study the response of both these antioxidant defense mechanisms in the lungs of neonatal and adult rats during continuous exposure to $96-98 \%$ oxygen.

\section{MATERIALS AND METHODS}

Neonatal animals used for these studies were Sprague-Dawley albino rats bred and raised in the Animal Care Center at The University of Iowa. In each experiment, paired litter mates from several litters were randomly assigned to either the oxygenexposed or air-exposed control groups. A foster mother was then provided for each mixed litter. Unless otherwise specified, male and female rats of age 4-7 days were used. Male SpragueDawley albino rats (275-325 g), obtained from BioLab Corporation (St. Paul, MN), were used in the adult studies.

Both neonatal and adult rats were continuously exposed to either oxygen or room air in identical stainless steel exposure chambers (11). The oxygen and $\mathrm{CO}_{2}$ levels in the chamber were monitored continuously with Beckman model OM-11 and LB-2 gas analyzers (Beckman Instruments, Inc., Schiller Park, IL). The oxygen concentration was maintained at $96-98 \%$ and the $\mathrm{CO}_{2}$ concentration was less than $0.4 \%$ throughout the exposure period. The temperature of the chamber was $24-26^{\circ}$ and the vapor pressure $10-15 \mathrm{~mm} \mathrm{Hg}$. Animals were fed Wayne Lab-Blox pellet diet and given water ad libitum. The foster mothers were interchanged daily between litters exposed to oxygen and room air in order to avoid oxygen intoxication of the mothers and to minimize differences in nursing abilities. The chambers were opened daily for $15 \mathrm{~min}$ for cleaning, to change food and water, and to remove animals to be killed.

Animals were killed daily by decapitation and their lungs were carefully perfused with ice-cold isotonic buffer $(0.1 \mathrm{M}$ potassium phosphate, $0.15 \mathrm{M} \mathrm{KCl}, \mathrm{pH} \mathrm{7.4)} \mathrm{through} \mathrm{the} \mathrm{pulmo-}$ nary artery. The lungs were then trimmed of extraparenchymal trachea-bronchial and vascular tissue and homogenized for 2 $\min$ in a $1: 15(\mathrm{w} / \mathrm{v})$ dilution with ice-cold $0.005 \mathrm{M}$ phosphate buffer, pH 7.8, using a Sorvall Omnimixer (Ivan Sorvall Inc., Newtown, CT). For neonatal animal samples, lung tissue was pooled from four to eight rat pups. SOD, GSH, and DNA levels were determined in the lung homogenates and GP, GR, and G-6-PD activities were determined in the $15,000 \times g$ lung supernatant. SOD activity was determined by the standard determination of the inhibition of the xanthine and xanthine oxidase-catalyzed reduction of ferricytochrome $c$ (23). DNA was determined according to the method described by Richards (32). GSH was determined by the enzymatic method of Klotsch and Bergmeyer (16) as modified by Delucia et al. (8). GP activity of the cytosol fraction was determined by coupling peroxide reduction to NADPH oxidation through GR using $\mathrm{H}_{2} \mathrm{O}_{2}$ as substrate (28). Cytosol GR activity was determined by following NADPH disappearance (31). G-6-PD activity was determined by the method as described by Langdon (19). Lung enzyme activities, DNA, and GSH levels were expressed on a per lung basis as percentage of control values.

For histologic studies, three adult rats alive at the end of 72 hr of oxygen exposure were killed. The thoracic cavity was opened, the trachea was cannulated, and $10 \%$ buffered formalin was instilled via the airway at the perfusion pressure of 25-30 $\mathrm{cm}$ water. Three neonatal animals were also killed at the end of 5 days of oxygen exposure and their lungs were fixed by immersion in buffered formalin. Various areas of the lung were embedded in paraffin and stained with hematoxylin and eosin for light microscopic evaluation of lung morphology.

Another group of neonatal rats was exposed to either air or 96-98\% oxygen for a total period of 4 days. At the end of the exposure period, the animals were killed and the activity of the following enzymes in the lung were measured: alkaline phosphatase (EC 3.1.3.1) (21) and $\beta$-glucuronidase (EC 2.3.1.31) (10) were determined in the lung homogenate; glutamic dehydrogenase (EC 1.4.1.3) (36), fructose-1,6-diphosphate aldolase (EC 4.1.2.13) (30) and catalase (EC 1.11.1.6) (13) were analyzed in the $15,000 \times g$ lung supernatant.

Student's $t$-test and paired $t$-test were used for statistical analysis of results from adult and newborn animals, respectively. $P$ values equal to or less than 0.05 were considered significant (two-tailed).

\section{RESULTS}

In a preliminary study to assess the effect of age on oxygen toxicity, the mortality was determined among rats of varying ages (newborn to adult) exposed to $72 \mathrm{hr}$ of $96-98 \%$ oxygen. The results are shown in Figure 1. Under the conditions of these studies, all rats of age 4 weeks or younger survived the 3 days of oxygen exposure. However, only $25 \%$ of rats over 7 weeks of age were alive at the end of this exposure period.

Experiments were then carried out to compare the pulmonary biochemical responses of the two selected age groups of rats, namely the neonatal rat (4-7 days old) and the adult rat (approximately 80 days old), to $96-98 \%$ oxygen exposure. Continuous exposure of the adult rats to $96-98 \%$ oxygen was terminated at the end of the third day because of the already high mortality rate at this time. The neonatal rat experiment was continued for a total period of 5 days, at which time all the neonatal rats were still alive.

The lung weight to body weight ratio was calculated to provide an index of pulmonary edema (Table 1). Neonatal animals showed no significant change in the lung weight to body weight ratio throughout the $120 \mathrm{hr}$ of oxygen exposure, whereas the 72-hr oxygen-exposed adult rats showed a significant increase in this parameter over the adult air-exposed controls. The above findings were consistent with the gross autopsy and light microscopic examinations of the neonatal and adult rat lungs. The oxygen-exposed adults uniformly displayed fluid in their thoracic cavity, whereas none of the neonatal rats had any gross evidence of pulmonary edema at autopsy. Light microscopic characteristics of the 72-hr oxygen-exposed adult rat lung included thickened alveolar septa, fluid-filled alveolar spaces, focal areas of alveolar hemorrhage, and accumulation of alveolar macrophages within the alveolar space. Examination of $120-\mathrm{hr}$ oxygen-exposed neonatal rat lungs revealed only minimal alveolar wall thickening and alveolar edema.

Table 2 indicates that the lung DNA content remained unchanged in adult rats throughout the oxygen exposure period.

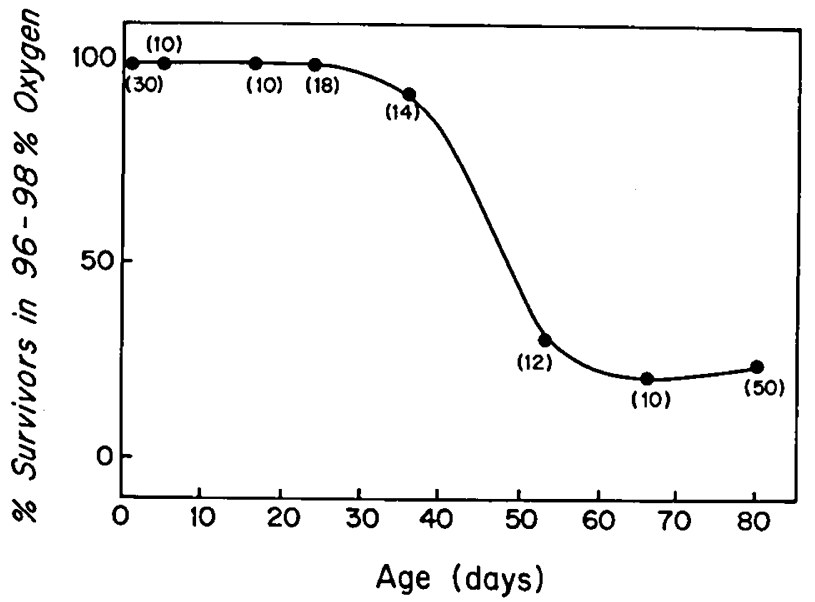

Fig. 1. Percentage of survival in rats of varying ages after exposure to $96-98 \%$ oxygen for $72 \mathrm{hr}$. Numbers in parentheses indicate the number of animals in each age group that were exposed to oxygen. 
Table 1. Effect of 96-98\% oxygen exposure on lung weight to body weight ratio in neonatal and adult rats

\begin{tabular}{ccc}
\hline & \multicolumn{2}{c}{ Lung wt/body wt $\left(\times 10^{-2}\right)^{1}$} \\
\cline { 2 - 3 } Treatment & Neonate $(n=4)$ & Adult $(n=6-10)$ \\
\hline $24 \mathrm{hr}$ & & \\
$\mathrm{Air}$ & $1.63 \pm 0.04$ & $0.455 \pm 0.004$ \\
$\mathrm{O}_{2}$ & $1.61 \pm 0.15$ & $0.441 \pm 0.019$ \\
$48 \mathrm{hr}$ & & \\
$\mathrm{Air}$ & $1.62 \pm 0.01$ & $0.474 \pm 0.040$ \\
$\mathrm{O}_{2}$ & $1.74 \pm 0.04$ & $0.553 \pm 0.050$ \\
$72 \mathrm{hr}$ & & \\
$\mathrm{Air}$ & $1.63 \pm 0.04$ & $0.452 \pm 0.012$ \\
$\mathrm{O}_{2}$ & $1.66 \pm 0.05$ & $0.882 \pm 0.046^{2}$ \\
$96 \mathrm{hr}$ & & \\
$\mathrm{Air}$ & $1.61 \pm 0.11$ & \\
$\mathrm{O}_{2}$ & $1.52 \pm 0.05$ & \\
$120 \mathrm{hr}$ & & \\
$\mathrm{Air}$ & $1.53 \pm 0.20$ & \\
$\mathrm{O}_{2}$ & $1.47 \pm 0.11$ & \\
\hline
\end{tabular}

1 Values shown are means $\pm \mathrm{SE}$.

${ }^{2}$ Significantly different from the respective air-exposed control values $(P<0.05)$

Table 2. Effect of $96-98 \%$ oxygen exposure on DNA content in neonatal and adult rat lungs

\begin{tabular}{ccc}
\hline & \multicolumn{2}{c}{ Lung DNA content (mg/lung)' } \\
\cline { 2 - 3 } Treatment & Neonate $(n=4)$ & Adult $(n=6-10)$ \\
\hline $24 \mathrm{hr}$ & & \\
$\mathrm{Air}$ & $1.6 \pm 0.2$ & $7.3 \pm 0.5$ \\
$\mathrm{O}_{2}$ & $1.6 \pm 0.2$ & $7.7 \pm 1.0$ \\
$48 \mathrm{hr}$ & & \\
$\mathrm{Air}$ & $1.7 \pm 0.1$ & $7.5 \pm 0.8$ \\
$\mathrm{O}_{2}$ & $1.6 \pm 0.2$ & $7.0 \pm 0.5$ \\
$72 \mathrm{hr}$ & & \\
$\mathrm{Air}$ & $2.1 \pm 0.2$ & $9.5 \pm 0.5$ \\
$\mathrm{O}_{2}$ & $1.7 \pm 0.2^{2}$ & \\
$96 \mathrm{hr}$ & & \\
$\mathrm{Air}$ & $1.8 \pm 0.2$ & \\
$\mathrm{O}_{2}$ & $1.5 \pm 0.1$ & \\
$120 \mathrm{hr}$ & & \\
$\mathrm{Air}$ & $2.4 \pm 0.1$ & \\
$\mathrm{O}_{2}$ & $1.7 \pm 0.2^{2}$ & \\
\hline
\end{tabular}

' Values shown are means $\pm \mathrm{SE}$.

${ }^{2}$ Significantly different from the respective air-exposed control values $(P<0.05)$.

Lung DNA content in the $72-$ and $120-\mathrm{hr}$ oxygen-exposed neonatal rats was, however, significantly lower than the respective air-exposed controls whose levels increased with age.

The lung biochemical responses of the oxygen-induced neonatal and adult rats are shown in Figures 2-6. Twenty-four hours after the start of oxygen exposure, SOD activity in the neonatal rat lung increased to $144 \%$ of control (Fig. 2). This initial increase in SOD activity declined to about $12 \%$ on day 2 and remained between 10 and $15 \%$ higher than control activity up to the end of the fifth day of oxygen exposure. The oxygenexposed adult rat lung, in contrast, consistently showed a progressive decrease in SOD activity.

A similar pattern was seen with the effect of oxygen on GP (Fig. 3), GR (Fig. 4), GSH (Fig. 5), and G-6-PD (Fig. 6) activities. The lungs of the oxygen-exposed neonatal rats showed a progressive increase in activity levels which plateaued after 34 days of exposure. Peak values (expressed as a percentage of air control) in oxygen-exposed neonatal lungs were; GP (126\%), GR $(122 \%)$, GSH $(176 \%)$, and G-6-PD (151\%). The oxygenexposed adult rats failed to show any increase in GP and GR

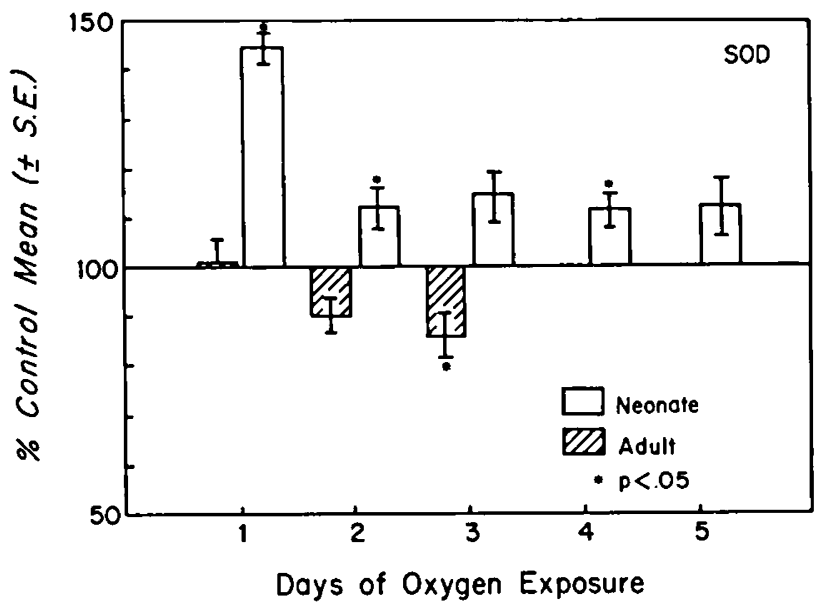

Fig. 2. Effect of 96-98\% oxygen exposure on SOD activity in neonatal and adult rat lungs. Each bar represents the percentage of control mean $( \pm \mathrm{SE})$ of $n=4$ for neonatal and $n=6-10$ for adult studies. Mean control SOD activities (units per lung) were: $2020 \pm 140$ for adult rat; $240 \pm 58$ for neonatal rat at day 5 .

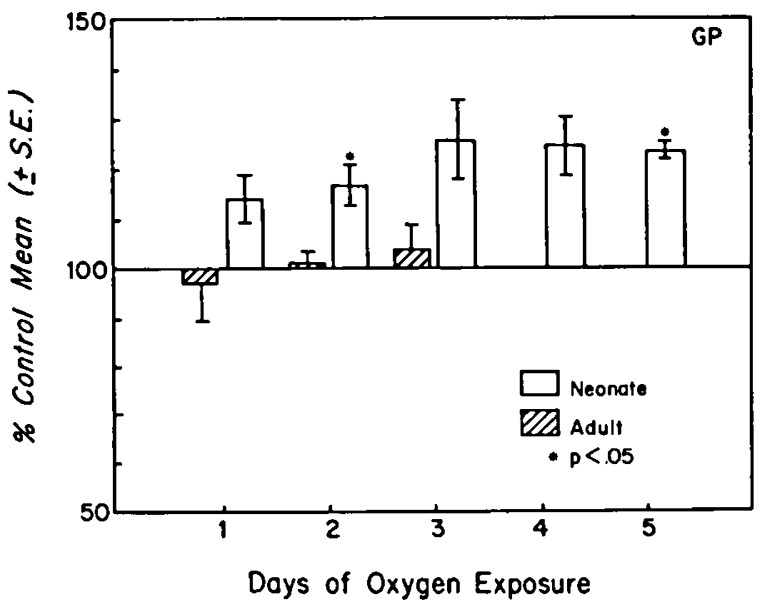

Fig. 3. Effect of $96-98 \%$ oxygen exposure on GP activity in neonatal and adult rat lungs. Each bar represents the percentage of control mean $( \pm \mathrm{SE})$ of $n=4$ for neonatal and $n=6-10$ for adult studies. Mean control GP activities (micromoles of NADPH oxidized per min per lung) were: $16.6 \pm 1.1$ for adult rat; $1.02 \pm 0.29$ for neonatal rat at day 5 .

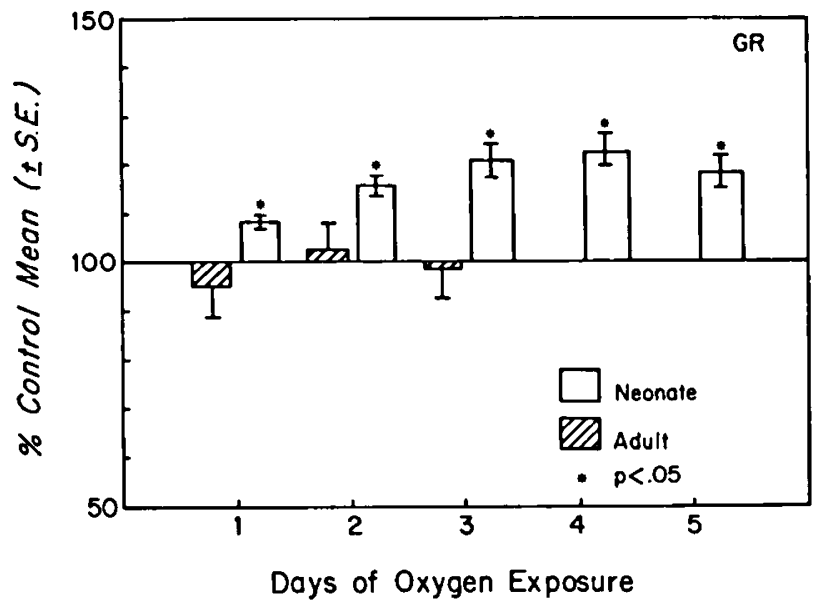

Fig. 4. Effect of $96-98 \%$ oxygen exposure on GR activity in neonatal and adult rat lungs. Each bar represents the percentage of control mean $( \pm \mathrm{SE})$ of $n=4$ for neonatal and $n=6-10$ for adult studies. Mean control GR activities (micromoles of NADPH oxidized per min per lung) were: $2.49 \pm 0.06$ for adult rat; $0.234 \pm 0.024$ for neonatal rat at day 5 . 


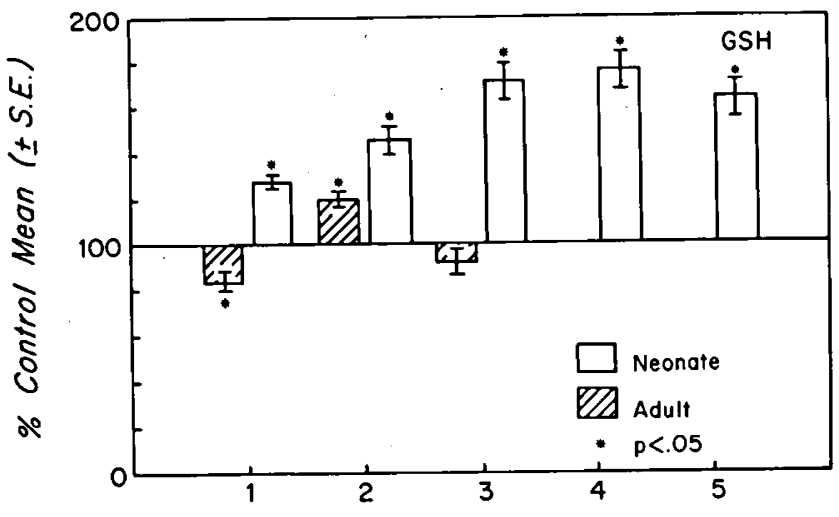

Days of Oxygen Exposure

Fig. 5. Effect of 96-98\% oxygen exposure on GSH level in neonatal and adult rat lungs. Each bar represents the percentage of control mean ( \pm SE) of $n=4$ for neonatal and $n=6-10$ for adult studies. Mean control GSH levels (micromoles per lung) were: $1.45 \pm 0.03$ for adult rat; $0.249 \pm 0.046$ for neonatal rat at day 5 .

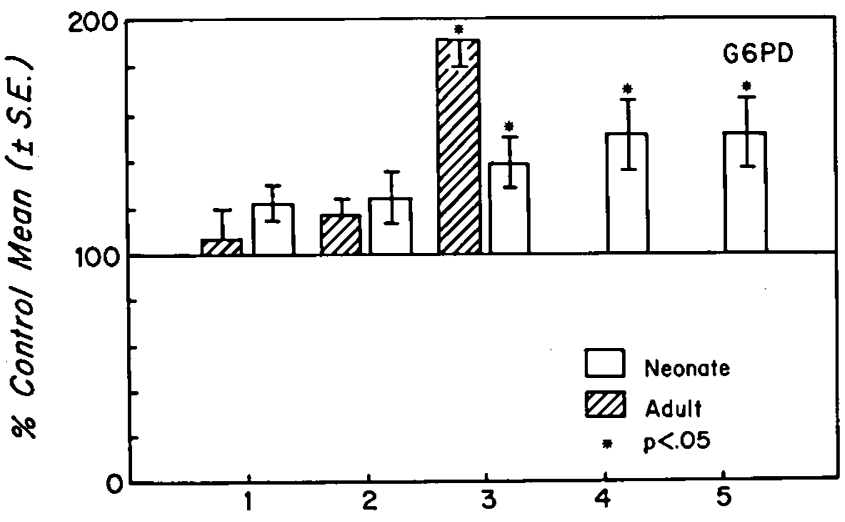

Days of Oxygen Exposure

Fig. 6. Effect of 96-98\% oxygen exposure on G-6-PD activity in neonatal and adult rat lungs. Each bar represents the percentage of control mean $( \pm \mathrm{SE})$ of $n=4$ for neonatal and $n=6-10$ for adult studies. Mean control G-6-PD activities (micromoles of NADPH reduced per min per lung) were: $2.13 \pm 0.08$ for adult rat; $0.180 \pm$ 0.045 for neonatal rat at day 5 .

activities or of GSH levels in their lungs with the exception of a small but significant increase of GSH level at the second day of oxygen exposure. G-6-PD was, however, significantly elevated in the 72-hr oxygen-exposed adult rats.

To determine whether the increased activity was confined to the pulmonary antioxidant enzymes, additional lung enzyme studies were conducted in oxygen-exposed neonatal rats (Table 3 ). Four days of oxygen exposure were chosen because the activity of most of the pulmonary antioxidant enzymes studies (Figs. 3-5) was found to peak at this time. Activity of pulmonary alkaline phosphatase, a ubiquitous, nonspecific phosphatase; $\beta$ glucuronidase, a drug-metabolizing enzyme; fructose-1,6-diphosphate aldolase, a glycolytic enzyme; and glutamic dehydrogenase, a transaminase which catalyzes the formation of amino acids from Kreb's cycle intermediates, in oxygen-exposed neonatal rats was not significantly different from that of air-exposed controls. Activity of catalase, an enzyme which sequesters $\mathrm{H}_{2} \mathrm{O}_{2}$ formed from the SOD dismutation reaction and can be considered as part of the pulmonary antioxidant defense system, was significantly increased in oxygen-exposed neonatal rat lung as compared to the air-exposed control.

\section{DISCUSSION}

Although oxygen-induced lung toxicity has been shown to be age-dependent (References 5, 18, 29, Fig. 1), the mechanism
Table 3. Effect of oxygen exposure on activity of other pulmonary enzymes in neonatal rat ${ }^{1}$

\begin{tabular}{lcc}
\hline Enzymes & Air & Oxygen \\
\hline $\begin{array}{l}\text { Alkaline phosphatase (nmol p-nitro- } \\
\text { phenol liberated/hr/lung) }\end{array}$ & $134 \pm 11$ & $127 \pm 10$ \\
$\begin{array}{c}\beta \text {-Glucuronidase ( } \mu \text { mol phenol- } \\
\text { phthalein glucuronide hydrolyzed/ } \\
\text { hr/lung) }\end{array}$ & $54.7 \pm 3.9$ & $60.1 \pm 1.6$ \\
$\begin{array}{c}\text { Glutamic dehydrogenase (nmol } \\
\text { NADH oxidized/min/lung) }\end{array}$ & $100 \pm 10$ & $78 \pm 16$ \\
$\begin{array}{c}\text { Fructose-1,6-diphosphate aldolase } \\
\text { (nmol NADH oxidized/min/lung) }\end{array}$ & $447 \pm 30$ & $510 \pm 11$ \\
\begin{tabular}{l} 
Catalase (IU/lung) \\
\hline
\end{tabular} & $620 \pm 10$ & $1020 \pm 60^{3}$ \\
\hline
\end{tabular}

1 Neonatal rats (4-7 days old) were exposed to either air or $96-98 \%$ oxygen for 4 days $(96 \mathrm{hr})$. Each value represents the mean $\pm \mathrm{SE}$ of four to six determinations.

${ }^{2}$ One international unit (IU) is defined as the amount of enzyme which reacts with $1 \mu \mathrm{mol} \mathrm{H}_{2} \mathrm{O}_{2} / \mathrm{min}$.

${ }^{3}$ Significantly different from the air-exposed control $(P<0.05)$.

to explain this phenomenon remains unclear. We propose that young animals, when challenged with oxygen, have a more rapidly adaptive pulmonary antioxidant protective capacity, i.e., the SOD and the GSH systems, which provides a mechanism(s) for their increased tolerance to hyperoxia-induced lung injury as compared to the adults.

We have previously reported that exposure of newborn and neonatal animals to $24 \mathrm{hr}$ of $85 \%$ oxygen produced a significant increase in pulmonary SOD activity $(1,11)$. Similar findings were observed in the present study in neonatal rats exposed to 96-98\% oxygen (Fig. 2). Adult animals, on the other hand, when exposed to sublethal concentrations of oxygen $(85 \%)$ (34), did not show any increase in lung SOD activity $24 \mathrm{hr}$ after hyperoxic exposure (11). When exposed to a lethal concentration of oxygen (96-98\%) in this study, adult rats showed a significant decrease in the activity of lung SOD (Fig. 2), which correlates with their low survival rate under these conditions. The increase in SOD activity in the neonatal animal was particularly striking in the first $24 \mathrm{hr}$ of oxygen exposure (Fig. 2 ). It is conceivable that this rapid early adjustment of pulmonary SOD activity in neonatal animals, not observed in adult animals, may be of paramount importance in preventing the initiation of lung damage early in the course of oxygen exposure (11). Catalase, an enzyme which detoxifies the $\mathrm{H}_{2} \mathrm{O}_{2}$ formed from the SOD dismutation reaction, was also found to be significantly increased in $96-\mathrm{hr}$ oxygen-exposed neonatal rat lung (Table 3).

Examination of the glutathione system in the lungs of neonatal rats which survived 5 days of $96-98 \%$ oxygen exposure with no evidence of respiratory distress showed a progressive increase in the activity levels of pulmonary GP, GR, and GSH (Figs. 3$5)$. In accordance with the proposed protective role of the glutathione system $(3,15)$, adult rats, which succumbed within 3 days of oxygen exposure, did not show any significant changes in the activity levels of pulmonary GP, GR, and GSH with the exception of a small but significant increase in GSH levels after $48 \mathrm{hr}$ of oxygen exposure. The potential contribution of G-6$P D$ in the protection against oxygen-induced lung injury is unclear, since G-6-PD was found to increase in both neonatal and adult rat lungs (Fig. 6).

The increase in pulmonary antioxidant enzyme activity in oxygen-exposed neonatal rat does not appear to be a generalized enzyme response since the activity of enzymes not related to the pulmonary antioxidant defense system remained essentially unchanged following the oxygen challenge (Table 3 ). It should be noted that the increase in protective enzyme activities and GSH levels in neonatal animals occurs at a time when the intracellular DNA synthesis appears to be inhibited (Table 2 and Reference 27). The increase in the production of these protective enzymes and GSH possibly at the expense of other 
cellular constituents, may reflect a vital adaptive response of the neonatal animal to oxygen.

From the present data, it is reasonable to postulate that SOD comprises the major defensive factor in neonatal animals early in oxygen toxicity. As early as $24 \mathrm{hr}$ after exposure, SOD activity in the neonatal lung is maximally increased (Fig. 2). As the course of oxygen exposure progresses, the increased production of superoxide anion may saturate the superoxide dismutase system. Excess superoxide anion and/or lipid peroxides may act as the stimulus to augment the activity of the glutathione system, which then assumes a major role in the defense against oxygen-induced pulmonary injury. The degree of oxygen-induced lung damage would thus appear to be governed by the sensitive balance in the lung cell between the generation of toxic intermediates of oxygen and the execution of the antioxidant defense apparatus. Pulmonary damage would occur only if the protective mechanism is overwhelmed by excess rates of generation of superoxide anion or other toxic intermediates, such as hydroxyl free radicals (9). During exposure to high concentrations of oxygen, the intracellular production of superoxide anion is believed to be increased $(24,25)$. Increases in the lung complement of SOD, GR, GP, and GSH in neonatal rat during oxygen challenge should permit a delay in onset and/ or minimization of oxygen-induced lung injury in contrast to the situation in adult animals. Additional studies are warranted to more precisely define the cell types in the lung that account for the observed biochemical alterations and correlate them with the site and nature of oxygen-induced lung damage. The changes in enzyme activities and GSH level observed in the neonatal rat lung may be in reality of a much greater magnitude if the increase is found to occur in a specialized cell group.

A further understanding of the antioxidant defense mechanism in the lung has potentially great importance in neonatal respiratory disease and therapy. Neonatal respiratory disease may be aggravated or may even develop as a result of the lack of a normal response by the neonatal pulmonary protective systems to environmental stimuli as suggested previously for bronchopulmonary dysplasia (11). Identification of agents or drugs that may induce or augment these protective enzymes may provide a means to allow for the safer use of high oxygen therapy in neonatal intensive care.

\section{REFERENCES AND NOTES}

1. Autor, A. P., Frank, L. and Roberts, R. J.: Developmental characteristics of pulmonary superoxide dismutase: Relationship to idiopathic respiratory distress syndrome. Pediat. Res., 10: 154 (1976).

2. Bonikos, D. S., Bensch, K. G., and Northway, W. H.: Oxygen toxicity in the newborn: The effect of chronic continuous 100 percent oxygen exposure on the lungs of newborn mice. Amer. J. Pathol., 85: 623 (1976).

3. Chow, C. K., and Tappel, A. L.: An enzymatic protective mechanism against lipid peroxidation damage to lungs of ozone-exposed rats. Lipids, 7: 518 (1972).

4. Chvapil, M., and Peng, Y. M.: Oxygen and lung fibrosis. Arch. Environ. Health, 30: 528 (1975).

5. Clark, J. M., and Lambertsen, C. J.: Pulmonary oxygen toxicity: A review. Pharmacol. Rev., 23: 37 (1971).

6. Crapo, J. D., and Tierney, D. F.: Superoxide dismutase and pulmonary oxygen toxicity. Amer. J. Physiol., 226: 1401 (1974).

7. Crapo, J. D., and McCord, J. E.: Oxygen-induced changes in pulmonary superoxide dismutase assayed by antibody titrations. Amer. J Physiol. 231: 1196 (1976).

8. Delucia, A. J., Mustafa, M. G., Hussain, M. Z., and Cross, C. E.: Ozone interaction with rodent lung. III. Oxidation of reduced glutathione and formation of mixed disulfides between protein and nonprotein sulfhydryls. J. Clin. Invest., 55: 794 (1975).

9. Feeney, L., and Berman, E. R.: Oxygen toxicity: Membrane damage by free radicals. Invest. Ophthalmol., 15: 789 (1976).

10. Fishman, W. H.: $\beta$-Glucuronidase. In: H. U. Bergmeyer: Methods of Enzymatic Analysis, p. 869 (Academic Press, New York, 1965)

11. Frank, L., Autor, A. P., and Roberts, R. J.: Oxygen therapy and hyaline membrane disease: The effect of hyperoxia on pulmonary superoxide dismutase activity and the mediating role of plasma or serum. J. Pediat. 90: 105 (1977)

12. Harrison, G. A.: Ultrastructural changes in rat lung during long-term exposure to oxygen. Exp. Med. Surg., 29: 96 (1971).

13. Holmes, R. S. and Masters, C. J.: Epigenetic interconversions of the multiple forms of mouse liver catalase. Fed. Expl. Biochem. Soc. Lett., 11: 45 (1970).

14. James, S. L., and Lanman, J. T.: History of oxygen therapy and retrolental fibroplasia. Pediatrics, 57: 591 (1976)

15. Kimball, R. E., Reddy, K., Peirce, T. H., Schwartz, L. W., Mustafa, M. G., and Cross, C. E.: Oxygen toxicity: Augmentation of antioxidant defensemechanisms in rat lung. Amer. J. Physiol., 230: 1425 (1976).

16. Klotsch, H., and Bergmeyer, H. U.: Glutathione. In: H. U. Bergmeyer: Methods of enzymatic analysis, pp. 363-366 (Academic Press, New York, 1965).

17. Koppenol, W. H.: Reactions involving singlet oxygen and the superoxide anion. Nature, 262: 420 (1976).

18. Kyle, J. D.: The effects of $100 \%$ oxygen inhalation on adult and newborn rat lungs. South. Med. J., 58: 1952 (1965).

19. Langdon, R. G.: Glucose-6-phosphate-dehydrogenase from erythrocytes. In: S. P. Colowick and N. P. Kaplan: Methods in Enzymology, Vol. 9, pp. 126-131 (Academic Press, New York, 1966).

20. Lavelle, F., Michelson, A. M., and Dimitryevic, L.: Biological protection by superoxide dismutase. Biochem. Biophys. Res. Commun., 55: 350 (1973).

21. Linhardt, K., and Walter, K.: Phosphatases (phosphomonoesterases). In: H. U. Bergmeyer: Methods of Enzymatic Analysis, p. 779 (Academic Press, New York, 1965).

22. McCay, P. B., Gibson, D. D., Fong, K., and Hornbrook, K. R.: Effect of glutathione peroxidase activity on lipid peroxidation in biological membranes. Biochim. Biophys. Acta, 431: 459 (1976).

23. McCord, J. M., and Fridovich, I.: Superoxide dismutase: An enzymic function for erythrocuprein (Henocuprein). J. Biol. Chem., 244: 6049 (1969).

24. McCord, J. M., Beauchamp, C. O., Goscin, S., Misra, H. P., and Fridovich, I.: Superoxide and superoxide dismutase. In: Oxidases and Related Redox Systems (University Park Press, Baltimore, 1973).

25. Misra, H. P., and Fridovich, I.: The univalent reduction of oxygen by reduced flavins and quinones. J. Biol. Chem., 247: 188 (1972).

26. Northway, W. H., and Rosan, R. C.: Radiographic features of pulmonary oxygen toxicity in the newborn: Bronchopulmonary dysplasia. Radiology, 91: 49 (1968).

27. Northway, W. H., Rozeau, L., Petriceks, R., and Bensch, K. G.: Oxygen toxicity in the newborn lung: Reversal of inhibition of DNA synthesis in the mouse. Pediatrics, 57: 41 (1976).

28. Paglia, D. E., and Valentine, W. N.: Studies on the quantitative and qualitative characterization of erythrocyte glutathione peroxidases. J. Lab. Clin. Med., 70: 158 (1967).

29. Polgar, G., Antagnoli, W., Ferrigan, L. W., Martin, E. A., and Gregg, W. P.: The effect of chronic exposure to $100 \%$ oxygen in newborn mice. Amer. J. Med. Sci., 252: 580 (1966).

30. Rajkumar, T. V., Woodfin, B. M., and Rutter, W. J.: Fructose diphosphate aldolase. III. Aldolase B from (adult) rabbit liver. In: S. P. Colowick and N. O. Kaplan: Methods in Enzymology, Vol. 9, p. 491 (Academic Press, New York, 1966).

31. Ray, L. E., and Prescott, J. M.: Isolation and characteristics of glutathione reductase from rabbit erythrocytes. Proc. Soc. Exp. Biol. Med., 148: 402 (1975).

32. Richards, G. M.: Modifications of the diphenylamine reaction giving increased sensitivity and simplicity in the estimation of DNA. Anal. Biochem., 57: 369 (1974).

33. Rister, M., and Baehner, R. L.: The alteration of superoxide dismutase catalase, glutathione peroxidase, and NAD $(\mathrm{P}) \mathrm{H}$ cytochrome $c$ reductase in guinea pig polymorphonuclear leukocytes and alveolar macrophages during hyperoxia. J. Clin. Invest., 58: 1174 (1976).

34. Rosenbaum, R. M., Wittner, M., and Lenger, M.: Mitochondrial and other ultrastructural changes in great alveolar cells of oxygen-adapted and poisoned rats. Lab. Invest., 20: 516 (1969).

35. Saltzman, H. A., and Fridovich, I.: Oxygen toxicity. Introduction to a protective enzyme: Superoxide dismutase. Circulation, 48: 921 (1973).

36. Schmidt, E.: Glutamic dehydrogenase. In: H. U. Bergmeyer: Methods of Enzymatic Analysis, p. 779 (Academic Press, New York, 1965).

37. Stevens, J. B., and Autor, A. P.: Induction of superoxide dismutase by oxygen in the neonatal rat lung. J. Biol. Chem., 252: 3509 (1977).

38. Swyer, P. R., Boston, R. W., Murdock, A., Pare, C., Rees, E. P., Segal, S., and Sinclair, J. C.: Oxygen therapy in the newborn infant. J. Can. Med. Ass., 113: 750 (1975).

39. Tsai, S. H., Anderson, W. R., Strickland, M. B., and Pliego, M.: Bronchopulmonary dysplasia associated with oxygen therapy in infants with respiratory distress syndrome. Radiology, 105: 107 (1972).

40. Weissberg, J. B., and Crapo, J. D.: Hyperoxia and red cell 2,3-diphosphoglycerate. Toxicol. Appl. Pharmacol., 36: 41 (1976).

41. The authors acknowledge the valuable suggestions by Dr. A. P. Autor and the very able technical assistance of Mrs. Mary Jo Kline and Mr. Michael Reeves in these studies.

42. John Yam is a Procter and Gamble Predoctoral Fellow.

43. This research is supported by USPHS Grants GM 00141, GM 07013, GM 07069, and GM 12675, Health Professional Special Project Grant 07-D000008-05, and Clinical Pharmacology Trainee Grant 1F32 HL05415.

44. Requests for reprints should be addressed to: R. J. Roberts, Ph.D., M.D. The Toxicology Center, Department of Pharmácology, The University of Iowa, Iowa City, IA 52242 (USA).

45. Received for publication March 14, 1977.

46. Accepted for publication May 25, 1977. 